\title{
ЗНАЧЕНИЕ ЭКСПЕРИМЕНТА В ПРЕПОДАВАНИИ ОБЩЕЙ ХИМИИ В МЕДИЦИНСКОМ ВУЗЕ
}

\section{THE IMPORTANCE OF EXPERIMENT IN TEACHING GENERAL CHEMISTRY IN A MEDICAL UNIVERSITY}

\author{
I. Sychev \\ M. Aronova \\ A. Tararyshkin \\ T. Kolosova
}

Summary: The article examines the importance of a chemical experiment in the study of the subject General chemistry by first-year students. The ways of organizing an effective educational experiment in the subject of General Chemistry for the preparation of medical specialists are proposed. The ways of managing the process of forming professional and general educational competencies of future doctors are shown in the framework of laboratory and practical exercises, demonstration experiments and research experiment.

Keywords: medical university, General chemistry, chemical experiment, educational experiment, laboratory work, subject integration, first-year students.
Сычев Игорь Анатольевич

Д.б.н., дочент, Рязанский государственный медицинский университет имени академика И.П. Павлова

i.sytchev@rzgmu.ru

Аронова Мария Александровна

К.n.н., старший преподаватель, Рязанский государственный медицинский университет имени академика И.П. Павлова

mariia.aronova@mail.ru

Тарарышкин Александр Петрович

К.м.н., дочент, Рязанский государственный медицинский университет им. академика И.П. Павлова alextarar2017@mail.ru

Колосова Татьяна Юльевна

К.х.н., дочент, Рязанский государственный медицинский университет имени академика И.П. Павлова; tkkolosova@gmail.com

Аннотация: В статье рассматривается значение химического эксперимента при изучении студентами первых курсов дисциплины Общая химия. Предложены способы организации эффективного учебного эксперимента в курсе Общей химии при подготовке специалистов медицинского профиля. Показаны способы управления процессом формирования профессиональных и общеобразовательных компетенций будущих врачей в рамках реализации лабораторно-практических занятий, демонстрационных опытов и научноисследовательского эксперимента.

Ключевые слова: медицинский ВУЗ, Общая химия, химический эксперимент, учебный эксперимент, лабораторные работы, интеграция дисциплин, студенты-первокурсники.

ные процессы, Основы химической кинетики и термодинамики, Элементы количественного анализа. Во-вторых, количество лекционных и лабораторно-практических часов, в объёме которых необходимо изложить ряд тем, тесно интегрированных с курсами Биоорганической химии, Биохимии, Физики, Физиологии, Патологической физиологии, явно недостаточно, чтобы сформировать у студента необходимые знания, умения и навыки.

В-третьих, большинство первокурсников не обладают даже базовым уровнем практических навыков и умений, что связано с почти полным отсутствием в средней школе лабораторных опытов и демонстрационного эксперимента. В-четвертых, многие первокурсники, имея обширные теоретические знания по химии, не могут в полной мере оперировать ими в процессе обучения в ВУЗе. Связано это, прежде всего, со школьной методикой преподавания дисциплины, где на первый план выходит умение оперативно решать стандартные тестовые задания, не углубляясь в фундаментальные основы химии, как Буферные растворы, Окислительно-восстановитель- 
как науки. Такая модель обучения не способствует пониманию взаимосвязанности химических и биологических процессов, протекающих в живом организме.

Для преодоления всех вышеизложенных трудностей преподаватели кафедры общей химии Рязанского медицинского университета имени академика И.П. Павлова используют разнообразные пути решения.

Известно, что химия как наука нуждается в эксперименте в большей степени, чем другие дисциплины. Основные законы и теории Общей химии, правила и выводы были выведены в большинстве своем из экспериментальных данных $[1,4]$.

Под экспериментом понимают научно поставленный опыт, т. е. наблюдение исследуемого явления в учитываемых условиях, позволяющих следить за его ходом и воссоздавать его каждый раз при повторении тех же условий [3]. В определенном смысле, эксперимент является одним из критериев всех теоретических построений [2]. Поэтому нами в процессе преподавания курса Общей химии особое внимание уделяется различным видам учебного эксперимента, в частности - лабораторному практикуму и демонстрационным опытам.

Учебный химический эксперимент можно представить как специальным образом организованный фрагмент процесса обучения, направленный на познание объектов химии и развитие экспериментальной деятельности обучаемых [6]. Химический эксперимент курса Общей химии иллюстрирует наиболее сложные закономерности и понятия дисциплины и является составной частью учебного процесса [5], а также играет значимую роль в повышении заинтересованности первокурсников в изучаемой дисциплине и раскрытия их творческого потенциала.

В процессе обучения химии учебный эксперимент выполняет такие функции, как: информативную, критериальную, корректирующую, исследовательскую $[8,9,12]$.

В соответствии с целями и задачами обучения той или иной темы на кафедре используется лабораторный эксперимент как количественный, так и качественный; иллюстративный, демонстрационный, научно-исследовательский $[8,9,10]$.

Реализация химического эксперимента осуществляется на всех видах занятий: лабораторно-практических и лекционных.

Преподавателями кафедры тщательно отобраны темы для изучения дисциплины Общая химия, сформированы учебные программы и планы практических занятий и лекций, с учетом интеграции тематики практических занятий в структуру смежных дисциплин, изучаемых в медицинском ВУЗе на последующих курсах.

В процессе чтения лекций наиболее сложный теоретический материал иллюстрируется презентациями, включающие фильмы с демонстрационными экспериментами.

Лабораторно-практические занятия охватывают все изучаемые темы курса Общей химии и на каждом из них предусмотрено выполнение лабораторных работ или демонстрационных опытов. Сотрудниками нашей кафедры составлены расширенные лабораторные практикумы, в которых даны теоретические обоснования лабораторных работ, а также в рамках стандартных операционных процедур детально описаны этапы и методика их проведения. На всех видах занятий широко применяются средства наглядности (схемы, таблицы, плакаты, шаростержневые модели молекул) для облегчения восприятия и запоминания изучаемого материала.

Выполнение лабораторных работ позволяет студентам-медикам:

- приобретать и совершенствовать начальные практические умения и навыки, отрабатывать стандартные операционные процедуры;

- проводить реакции между веществами, интерпретировать полученные результаты в виде уравнений реакций, анализировать и обобщать результаты, формулировать выводы;

- легче усваивать сложный теоретический материал таких тем, как окислительно-восстановительные реакции, основы количественного анализа, буферные растворы, термодинамика, кинетика, наглядно иллюстрируя его;

- получать первые навыки исследовательской и научно-практической работы;

- знакомиться с элементами клинической лабораторной диагностики;

- готовиться к проведению экспериментов и лабораторных работ на последующих дисциплинах (Биоорганической химии, Физиологии, Фармакологии, Патологической физиологии, Биохимии);

- приобретать опыт творческой деятельности, а также опыт работы с учебной и научной литературой.

При выполнении лабораторных работ основными методами обучения являются самостоятельная работа студента и работа в малых группах под руководством преподавателя. Лабораторный эксперимент обычно проводится поэтапно:

- первый этап - подготовка студентов по технике безопасности, правила работы с химической посудой, приборами и реактивами, теоретическое 
обоснование постановки опыта;

- второй - планирование и демонстрация проведения каждого эксперимента с использованием видеороликов, подготовленных сотрудниками нашей кафедры;

- третий - проведение экспериментов студентами самостоятельно;

- четвертый - написание уравнений химических реакций, отображающих суть проводимых опытов;

- пятый - оценка полученных результатов и коррекция выводов о выявленных явлениях в ходе выполнения опытов.

Преподаватели кафедры привлекают первокурсников к научной работе кафедры (участие в студенческом научном обществе (СНО) и конференциях), в процессе которой будущие врачи осваивают различные виды экспериментальной работы, углубляют свои теоретические знания, развивают практические умения и навыки, что способствует формированию профессиональных компетенций.

В Рязанском медицинском университете существует электронная образовательная среда, которая при изучении дисциплины Общая химия позволяет в ряде случаев уйти от реального проведения химического эксперимента без потери качества получаемой информации [7]. На базе этой платформы (LMS MOODLE) силами преподавателей кафедры создана медиатека лабораторных работ по всем темам курса. Эти видеоролики используются студентами для систематизации теоретического и практического материала и самостоятельной работы при подготовке к лабораторно-практическим занятиям, контрольным работам и экзаменам. Необходимость такой медиотеки возникает при дистанционном обучении, иллюстративном эксперименте, а также при отработке студентами пропущенных занятий и отсутствии сложного оборудования, дорогостоящих или малодоступных реактивов. Так, у студентов появляется возможность изучения реакций с веществами, которые нежелательно использовать в учебном процессе, например, соединениями ртути, мышьяка, галогенов. При такой организации практикума отсутствуют ограничения по времени, студент может выполнять работу (или подготовиться к ней) во внеучебное время, повторять ее многократно.

Лабораторно-практические занятия на кафедре проводятся не только для проверки самоподготовки студентов по определенной теме, но и для реализации творческого взаимодействия преподавателей и студентов, когда активно используются различные методики обучения [11]. Преподаватель в процессе обсуждения теоретического материала и дискуссии работает как с отдельным студентом, отвечающим на поставленные вопросы, так и со всей группой. Каждый студент группы при таком подходе к процессу обучения должен следить за ходом обсуждения, описывать его самостоятельно в своей рабочей тетради, а при необходимости активно включаться в дальнейшее обсуждение и дискуссию с отвечающим студентом и с преподавателем. При этом используются не только метод беседы, но и фронтальный, устный и письменный опросы, а также работа у доски. Использование разнообразнейших методов контроля позволяет осуществлять коррекцию знаний, осознать их необходимость для последующего обучения и будущей профессиональной деятельности.

Таким образом, химический эксперимент в процессе изучения студентами дисциплины Общая химия дает возможность:

1. иллюстрировать основные теоретические положения Общей химии;

2. формировать практические умения и навыки, применяемые в клинической лабораторной деятельности;

3. развивать интерес к научно-исследовательской деятельности;

4. интегрировать основные положения Общей химии с другими дисциплинами медицинского ВУЗа;

5. оптимизировать совместную работу преподавателя и студентов;

6. способствовать адаптации первокурсников к новой для них образовательной среде.

Все выше перечисленное будет способствовать формированию профессиональных компетенций будущих врачей.

\section{ЛИТЕРАТУРА}

1. Арстанбекова Н.Б. Химический эксперимент как источник познания в преподавании курса «Неорганическая химия»// Проблемы современной науки и образования. - 2019. - доступ: https://cyberleninka.ru/article/n/himicheskiy-eksperiment-kak-istochnik-poznaniya-v-prepodavanii-kursa-neorganicheskayahimiya

2. Батаева Е.В., Демин В.В., Дунаев С.Ф. Эффективность демонстрационного эксперимента в лекционном курсе общей и неорганической химии для студентов нехимических специальностей// Вестник Московского университета, серия 2 Химия. - 2011. - т.52, - № 3.

3. Давыдова Г. Роль эксперимента в изучении химических дисциплин// Электронный справочник «Информио». - 2013. - 04.10. доступ http://www.informio.ru/publications/id585/Rol-yeksperimenta-v-izuchenii-himicheskih-disciplin 
4. Дзугаева М.А., Гаева А.А., Агаева Ф.А. Роль эксперимента в изучении химических дисциплин // Международный студенческий научный вестник. - 2016. - № 3-3.; URL: http://www.eduherald.ru/ru/article/view?id=15091 (дата обращения: 08.06.2020).

5. Ермаханов М.Н., Журхабаева Л.А., Адырбекова Г.М., Асылбекова Г.Т., Сабденова У.О., Куандыкова Э.Т. Химический эксперимент и его роль в методике обучения химии // Международный журнал прикладных и фундаментальных исследований. - 2016. - № 1-3. - C. 398-399; URL: https://applied-research. ru/ru/article/view?id=8520 (дата обращения: 08.06.2020).

6. Злотников Э.Г. Химический эксперимент как специфический метод обучения// «Первое сентября», «Химия» - 2007 - №24.

7. Князева Е.М. Лабораторные работы нового поколения // Фундаментальные исследования. - 2012. - № 6-3. - C. 587-590;URL: http://www.fundamentalresearch.ru/ru/article/view?id=30079 (дата обращения: 08.06.2020).

8. Кузурман, В.А. Методика преподавания химии: учеб.-метод. пособие / В.А. Кузурман, И.В. Задорожный; Владим. гос. ун-т им. А. Г. и Н. Г. Столетовых. Владимир: Изд-во ВлГУ, 2017. -89 с.

9. Литвинова Т.Н., Шельдешов Н.В., Скачко 0.В. Применение кластерного анализа в методическом исследовании процесса обучения общей химии студентов медицинского ВУЗа // Фундаментальные исследования. - 2004. - № 3. - C. 75-77; URL: http://www.fundamental-research.ru/ru/article/view?id=4786 (дата обращения: 08.06.2020).

10. Пак М.С. Теория и методика обучения химии: учебник для ВУЗов /М. С. Пак. - СПб: Изд-во РГПУ им. А.И. Герцена, 2015. - 306 с. 117-122

11. Романовский И.В., Ринейская 0.Н. Методологические вопросы преподавания органической и биоорганической химии в БГМУ// Военная медицина. 2019. - № 3. - C.2-7.

12. Яроватая М.А., Королёва И.П., Специфика преподавания химии студентам медицинского ВУЗа в рамках нового образовательного стандарта // Международный журнал экспериментального образования. - 2012. - № 4-2. - С. 292-294;URL: http://expeducation.ru/ru/article/view?id=4069 (дата $06 р$ ращения: 08.06.2020).

๑ Сычев Игорь Анатольевич (i.sytchev@rzgmu.ru), Аронова Мария Александровна (mariia.aronova@mail.ru),

Тарарышкин Александр Петрович (alextarar2017@mail.ru), Колосова Татьяна Юльевна (tkkolosova@gmail.com).

Журнал «Современная наука: актуальные проблемы теории и практики»

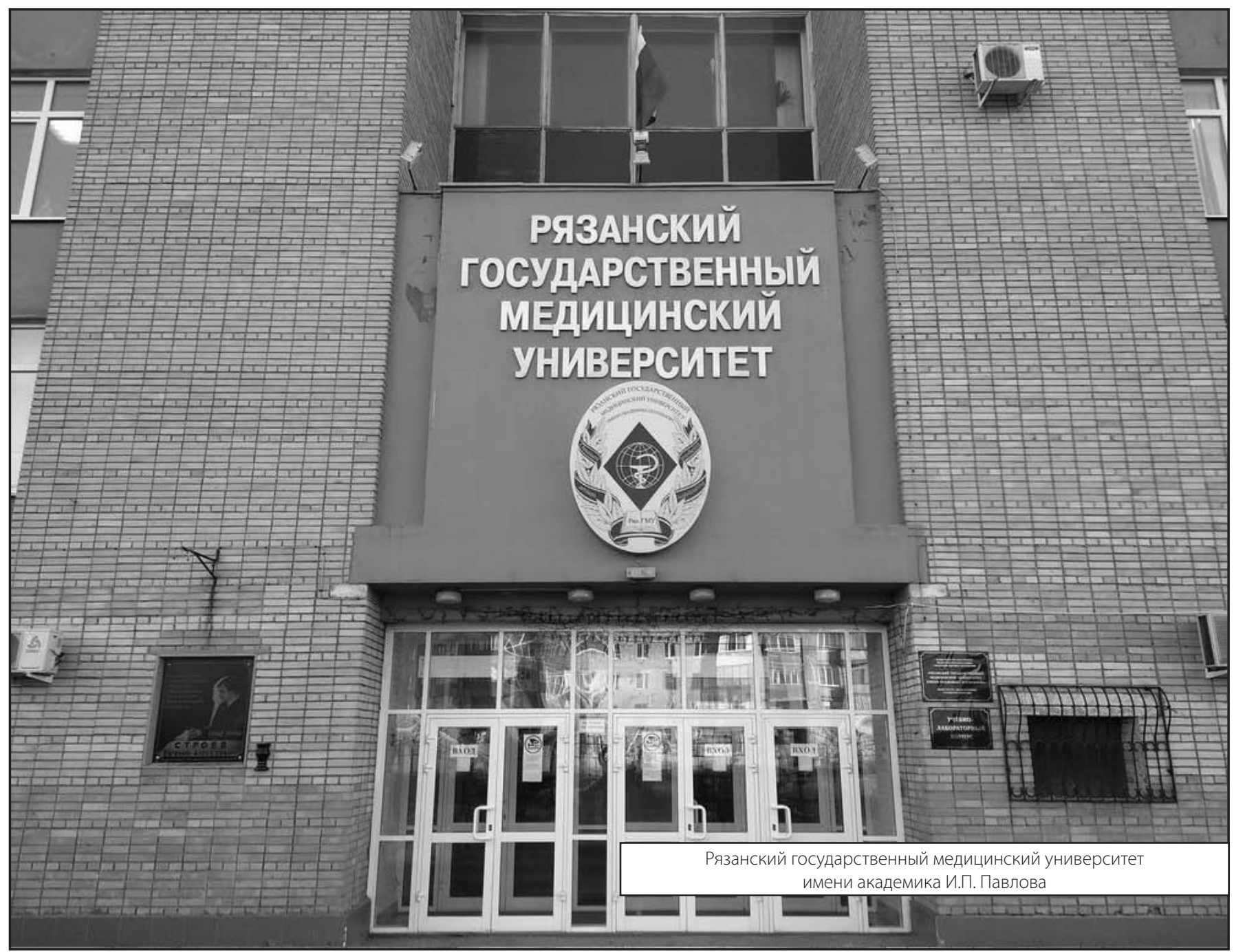

